\title{
Targeting KRAS in Cancer: Promising Therapeutic Strategies
}

\author{
Lisa Maria Mustachio 1,2,*, Anca Chelariu-Raicu ${ }^{3}$, Lorant Szekvolgyi ${ }^{4}$ (D) and Jason Roszik $5,6, *$ (D) \\ 1 Department of Epigenetics and Molecular Carcinogenesis, University of Texas MD Anderson Cancer Center, \\ Houston, TX 77030, USA \\ 2 Center for Cancer Epigenetics, University of Texas MD Anderson Cancer Center, Houston, TX 77030, USA \\ 3 Department of Obstetrics and Gynecology, University Hospital, Ludwig Maximilian University of Munich, \\ 80539 Munich, Germany; AChelariu@mdanderson.org \\ 4 Genome Architecture and Recombination Research Group, Department of Biochemistry and Molecular \\ Biology, MTA-DE Momentum, Faculty of Medicine, University of Debrecen, 4002 Debrecen, Hungary; \\ lorantsz@med.unideb.hu \\ 5 Department of Genomic Medicine, Division of Cancer Medicine, University of Texas MD Anderson Cancer \\ Center, Houston, TX 77030, USA \\ 6 Department of Melanoma Medical Oncology, Division of Cancer Medicine, University of Texas MD Anderson \\ Cancer Center, Houston, TX 77030, USA \\ * Correspondence: Lmustachio@mdanderson.org (L.M.M.); jroszik@mdanderson.org (J.R.); \\ Tel.: +1-832-750-4367 (L.M.M.); +1-713-745-2641 (J.R.)
}

check for updates

Citation: Mustachio, L.M.; Chelariu-Raicu, A.; Szekvolgyi, L.; Roszik, J. Targeting KRAS in Cancer: Promising Therapeutic Strategies. Cancers 2021, 13, 1204. https:// doi.org/10.3390/cancers13061204

Academic Editor: Rafael Rosell

Received: 24 February 2021

Accepted: 5 March 2021

Published: 10 March 2021

Publisher's Note: MDPI stays neutral with regard to jurisdictional claims in published maps and institutional affiliations.

Copyright: (c) 2021 by the authors Licensee MDPI, Basel, Switzerland. This article is an open access article distributed under the terms and conditions of the Creative Commons Attribution (CC BY) license (https:/ / creativecommons.org/licenses/by/ $4.0 /)$.
Simple Summary: Since the Kirsten rat sarcoma viral oncogene homolog $(K R A S)$ is mutated in about $25 \%$ of all human cancers and is at the center of pathways involved in tumorigenesis, it is necessary to compile and highlight the novel therapeutic strategies behind targeting this oncoprotein in cancer. Over the years, many have studied various methods to directly target KRAS with no success. Fortunately, there has been more success in targeting other proteins along the RAS pathway to yield a therapeutic response. However, some recent findings show promising results indicating that we are one step closer to developing an effective inhibitor that directly targets KRAS. The review presented here summarizes these recent findings and emphasizes the need to continue the search for the most optimal KRAS inhibitor that can be used to treat and potentially even cure certain tumor types.

Abstract: The Kirsten rat sarcoma viral oncogene homolog (KRAS) is mutated in approximately $25 \%$ of all human cancers and is known to be a major player promoting and maintaining tumorigenesis through the RAS/MAPK pathway. Over the years, a large number of studies have identified strategies at different regulatory levels to tackle this 'difficult-to-target' oncoprotein. Yet, the most ideal strategy to overcome KRAS and its downstream effects has yet to be uncovered. This review summarizes the role of $K R A S$ activating mutations in multiple cancer types as well as the key findings for potential strategies inhibiting its oncogenic behavior. A comprehensive analysis of the different pathways and mechanisms associated with KRAS activity in tumors will ultimately pave the way for promising future work that will identify optimum therapeutic strategies.

Keywords: cancer; EGFR; KRAS; MAPK; mutations; targeted-therapy

\section{Introduction}

Mutations in Kirsten rat sarcoma viral oncogene homolog (KRAS) are one of the most common oncogenic events in endodermal carcinomas [1]. The KRAS gene can simultaneously harbor multiple mutations that can potentiate tumor-promoting activity [2]. In fact, alterations in KRAS have been identified in $25 \%$ of all cancers, where some cancers like pancreatic cancer contain extremely high mutation rates $(90 \%)$, while others, such as prostate cancer, show lower mutation rates $(7 \%)[1,3]$. Not only do KRAS mutations promote and maintain tumorigenesis, they also increase the chance of resistance and poor 
prognosis, ultimately contributing to over one million deaths annually [1,3]. Even though mutations in other RAS isoforms, including the neuroblastoma RAS viral (v-ras) oncogene homolog (NRAS) and Harvey rat sarcoma viral oncogene homolog (HRAS) are prevalent in many cancer types, mutations in KRAS account for $85 \%$ of all RAS isoform mutations [1,3].

Scientists have been aiming to target KRAS for decades but have experienced difficulty in identifying strategies to target the smooth surface of the protein [4]. Activating mutations in KRAS increase the ability for GTP-loading and the GTP-binding pocket holds onto its substrate very tightly, making it difficult to displace [1,4]. Thus, constitutive activation of downstream signaling of the mitogen-activated protein kinase (MAPK) pathway occurs and regulates proteins involved in cell proliferation, development, inflammation, differentiation and apoptosis to promote cancer formation [1,3]. As a result, indirect strategies targeting downstream signaling of KRAS were attractive options but have still not resulted in desired outcomes. The epidermal growth factor receptor (EGFR) upstream of KRAS is also frequently mutated in various cancers and has also been sought as a therapeutic strategy to tackle KRAS mutant cancers [3]. Despite the seemingly many options to target KRAS, there have been many failed attempts in the past.

However, with more studies various new strategies have been identified to target $K R A S$ for cancer therapy [4]. New associations between KRAS and certain cancer phenotypes as well as the development of new agents are providing more hope in the battle against this difficult-to-target oncoprotein. This review will provide a summary of KRAS and its role in various tumors and provide a compilation of selected new insights and agents currently in the preclinical or clinical stages. (Figure 1) to treat cancers harboring KRAS mutations.

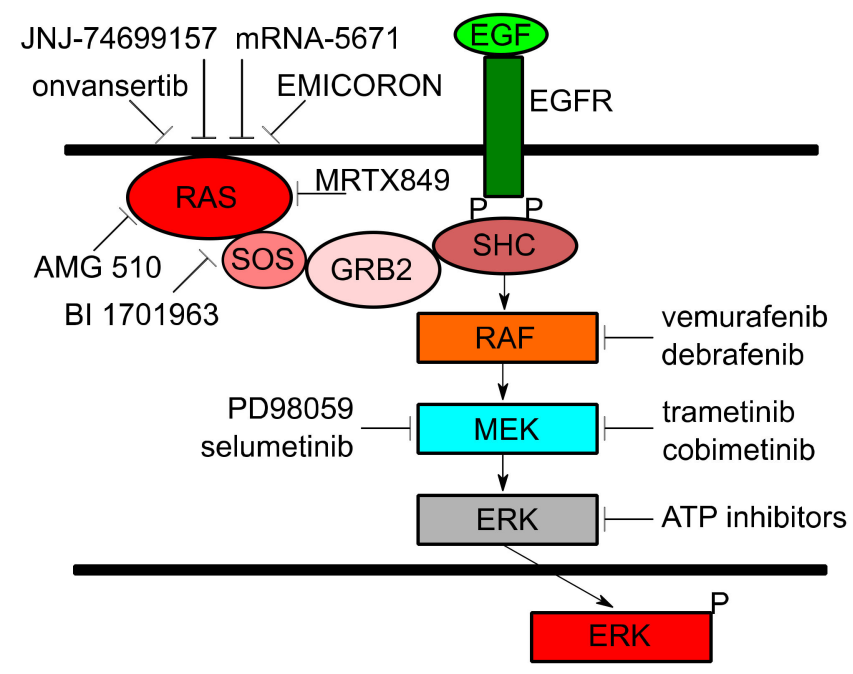

Figure 1. The role of KRAS and current agents in clinical or preclinical development.

\section{Blood Cancers}

RAS mutations are identified in $\sim 15 \%$ of acute myeloid leukemia (AML), $11 \%$ of adult $\mathrm{T}$ lineage acute lymphoblastic leukemia (T-ALL) and 30-40\% of multiple myeloma (MM) patients [5]. Approximately 5\% of AML cases harbor KRAS mutations and these mutations are thought to be early or initiating events in disease formation as well as acquired mutations during disease progression [5,6]. Overall survival and complete remission rate in AML patients are negatively influenced by the presence of KRAS mutations and KRAS was identified as a predictor of prognosis in these patients [7]. Similarly, the presence of KRAS mutations as well as mutations in NRAS were found to be associated with a shorter treatment-free survival in trisomy 12 chronic lymphocytic leukemia cases [8]. In pediatric B-cell precursor acute lymphoblastic leukemia (BCP-ALL), KRAS is mutated in approximately $44 \%$ of cases and is linked to relapse as well as chemotherapy resistance [9]. Interestingly, whole-genome sequencing revealed a $67 \%$ mutation rate in genes associated 
with the RAS signaling pathway [5]. In MM patients, KRAS mutations comprise $23 \%$ of cases and predict shorter overall survival as well as shorter progression-free survival [5].

Despite the high KRAS mutation rate in various leukemias and myeloma cases, the development of therapeutics specifically targeting KRAS has been a challenge. One study showed that high doses of cytarabine decrease the chance of relapse in RAS-mutated AML cases $[10,11]$. However, an attractive strategy to overcome KRAS is to target downstream effectors or other proteins in the RAS pathway. Homozygous mutant KRAS AML is less sensitive to mitogen-activated protein kinase kinase (MEK) inhibitors than cells containing a wild-type KRAS allele [12]. Even though attempts have been made to target MEK, mechanistic target of rapamycin (mTOR), protein kinase B (AKT), phosphatidylinositol 3-kinase (PI3K) and rapidly accelerated fibrosarcoma (RAF) to inhibit RAS signaling, no optimal strategies were identified since inhibition of one of these proteins results in the stimulation of compensatory mechanisms [13]. It is also important to mention that the RAS/RAF/MEK/extracellular signal-regulated kinase (ERK) pathway is activated in response to the administration of other drugs commonly used to treat leukemia [14]. Thus, targeting KRAS and its pathway in cancers of the blood has been challenging. Some preclinical studies have shown great promise in developing new methods to target the RAS pathway. One study unveiled that a novel competitive ATP inhibitor targeting ERK1 and ERK2 may have clinical benefit in KRAS mutant AML cases [14]. Inhibition of the KRAS activator SOS Ras/Rac guanine nucleotide exchange factor 1 (SOS1) is an effective approach when treating cancers driven by KRAS [15]. In addition, inhibiting SOS1 increases the sensitivity of KRAS mutant cancers to MEK inhibition. Since some AML cell lines harbor SOS1 mutations and are dependent on SOS1 for survival, a combination of SOS1 and MEK inhibitors may be an attractive strategy for the treatment of blood cancers containing KRAS mutations [16].

Interestingly, a new study revealed that the activation of KRAS wild-type alone is sufficient to induce oncogenic KRAS properties in cases of Down Syndrome (DS)-ALL [17]. Approximately $60 \%$ of DS-ALL cases harbor cytokine receptor-like factor 2 (CRLF2) rearrangements, $32 \%$ of cases harbor JAK2 mutations and $36 \%$ harbor mutations in the RAS-MAPK pathway. Both JAK2 and RAS pathway mutations are mutually exclusive. However, high CRLF2 levels and increased activation of JAK2 sufficiently activate wildtype KRAS in $80 \%$ of DL-ALL cases, suggesting that therapeutics inhibiting overstimulated KRAS are needed [17].

\section{Breast Cancer}

For quite some time, the role of KRAS in breast cancer has not been a point of focus since KRAS mutations are infrequent in this cancer type. However, out of all RAS proteins, $K R A S$ is the most frequently mutated RAS protein in breast cancer and is associated with poor prognosis as well as increased rate of metastasis [18]. More recent findings show that KRAS plays a role in promoting the activation of certain pathways involved in oncogenic behaviors contributing to breast tumorigenesis. For example, KRAS and PI3K have been found to cooperate in the production of de novo lipid biogenesis and RAS oncogenesis is exaggerated when the cyclin-dependent kinase inhibitor (p21WAF1/CIP1) is depleted in breast cancer [18-20]. Despite not frequently mutated in breast cancer, RAS proteins are known to be upregulated in breast tumors when compared to adjacent normal breast tissues and are correlated with p185/human epidermal growth factor receptor 2 (HER2) expression [21,22]. Both HER2 as well as EGFR are frequently overexpressed in breast cancer, amplify the RAS signaling pathway and are therapeutically targeted to treat this cancer type [18]. In another example, miRNA-382-5p enhances the progression of breast cancer through regulation of the RAS-like estrogen regulated growth inhibitor (RERG)/RAS/ERK axis [23]. Thus, even in the absence of genetic mutations, KRAS overexpression and signaling still contributes to breast oncogenesis. In addition to upstream effectors influencing RAS activity, certain regulators of KRAS, such as R-RasGTPases, mediate the interaction between estrogen and insulin signaling in breast cancer cells [24]. In addition, RAS protein activa- 
tor like 2 (RASAL2), a RasGAP gene, promotes the progression of triple-negative breast cancer through the activation of RAS-related C3 botulinum toxin substrate (RAC1) [25]. Specifically, many studies have linked RAS activity to the promotion of triple-negative breast cancer. For one, KRAS variants regulate the development of triple-negative breast cancer [26]. The RAS-MAPK pathway allows for immune-evasion in triple-negative breast cancer [27] and ERK1/2 phosphorylation levels are significantly increased in metastasized tumors stemming from a triple-negative breast primary tumor [28].

Currently, inhibitors have been produced that target downstream effector pathways of KRAS, including MEK inhibitors that are used to treat triple-negative breast cancer [29]. MEK inhibitors have shown some promising results in the treatment of other cancers. However, in breast cancer, MEK inhibitors do not improve overall survival [30] One study revealed that the MEK inhibitor PD98059 inhibited breast cancer cell proliferation but contributed to increased migration ability, explained by increased levels of $\beta$-catenin levels in the nucleus [30]. One certain fact is that the role of RAS in breast cancer cannot be ignored since it also has been associated with increased levels of resistance to cisplatin [31] and the tyrosine kinase inhibitor lapatinib [32] as well as influencing the response to tamoxifen [33].

\section{Colorectal Cancer}

The three RAS genes are mutated in $45 \%$ of all colorectal cancer cases, where KRAS is the most frequently mutated RAS isoform. Similarly, EGFR is overexpressed in $60-80 \%$ of colorectal cancers and specific antibody therapies, including cetuximab and panitumumab, have been used against EGFR and to target its downstream RAS/RAF/MEK/ERK signaling pathway $[34,35]$. However, with time, colorectal cancer patients experience resistance to EGFR inhibitors due to ability of RAS to activate the same downstream signaling pathway as EGFR that results through acquired resistance [36,37]. This suggests that the issue of KRAS activation needs to be tackled before EGFR inhibitors will be fully effective in more colorectal cancer cases. In light of these findings, the American Society of Clinical Oncology (ASCO) recommends testing both the EGFR and KRAS mutation status in patients with metastatic colorectal cancer who are candidates for anti-EGFR antibody therapy [38]. There have been various strategies aiming to directly target KRAS by altering its interaction with the cellular plasma membrane. However, farnesyl transferase inhibitors that made it to clinical trials appeared to be ineffective in treating cancer, including colorectal cancer cases [39]. There are some promising in vitro results showing that inhibitors against prenylbinding protein $P D E \delta$, which prevents $K R A S$ from localizing to the plasma membrane, inhibit the growth of KRAS mutant tumor cell lines [40,41].

Numerous attempts are still being made to directly target KRAS. One method is inhibiting the interaction between RAF and GTP-bound $K R A S$, which has shown strong anti-tumor activity in KRAS G12V mutated colorectal cancer xenografts [42]. The use of synthetic alkylating agents recognizing and alkylating adenine residues of mutant $K R A S$ have been developed and showed to inhibit the proliferation of KRAS mutant versus $K R A S$ wild-type colorectal cancer cell lines [43]. Since the direct targeting of KRAS has been difficult in all cancers, inhibitors focusing on targeting RAF/MEK/ERK have been generated. Pan-inhibitors that inhibit b-RAF proto-oncogene (BRAF) and c-RAF protooncogene (CRAF) as well as not activating the MAPK pathway in cancers harboring $K R A S$ mutations are being generated and show in vitro promising results [44]. KRAS mutant colorectal cancers have shown to be sensitive to a more recent G4 ligand known as EMICORON [41]. It was also shown that EMICORON in combination with chemotherapy improved anti-tumor efficacy as well as decreased both mRNA and protein expression levels of KRAS in colorectal cancer PDXs [34]. Lastly, another strategy to focus on regulating miRNAs associated with KRAS and its functions. For example, reduced levels of miR-143 increase cancer phenotypes of colorectal cancer cells [45].

One of the most promising therapies for the treatment of KRAS mutant colorectal cancers is onvansertib, a selective adenosine triphosphate competitive inhibitor of serine/threonine polo-like-kinase 1 (PLK1). It is currently being tested in a Phase $1 \mathrm{~b} / 2$ study 
along with the chemotherapeutic FOLFIRI and Avastin, which binds to vascular endothelial growth factor (VEGF) as a second-line treatment for metastatic colorectal cancer patients harboring KRAS mutations (Clinicaltrials.gov Identifier: NCT03829410 (accessed on 24 February 2021)). FOLFIRI is also being tested with MEK162 to evaluate the response rate, clinical benefit and safety parameters in advanced KRAS positive metastatic colorectal cancers (Clinicaltrials.gov Identifier: NCT02613650 (accessed on 24 February 2021)). Similarly, FOLFIRI is also being tested in combination with the virus based investigative therapy REOLYSIN and bevacizumab in FOLFIRI naïve patients with KRAS mutant metastatic colorectal cancer (Clinicaltrials.gov Identifier: NCT01274624 (accessed on 24 February 2021)). Patients enrolled in this study have shown a $100 \%$ clinical benefit. This study is expected to be completed in May 2022. In addition, the direct KRAS G12C inhibitor AMG 510, which will be described more in the lung and pancreatic cancer sections, has also showed great promise in reducing tumor size in colorectal cancer patients [46]. Lastly, the combination of the kinase inhibitor sorafenib and chemotherapeutic irinotecan (NEXIRI) has shown promising results as a second or later-line treatment for metastatic colorectal cancer patients with KRAS mutations as well as a treatment option for patients refractory to standard combined chemotherapies [47,48].

\section{Gynecological Cancers}

Gynecological malignancies account for $15-20 \%$ of all malignancies in women worldwide [49]. As in most cancers, genomic profiling of gynecological cancers has revealed new targets for tumor-specific treatment and the demand for individualized cancer therapy has increased in recent years. Spaans et al., investigated somatic mutations in gynecological cancers and found that PIK3A, PTEN and KRAS were the most frequently occurring mutations, with rates being 22,18 and $12 \%$, respectively [50]. Histologic types of ovarian cancer have been associated with different genetic alternations and both KRAS and BRAF mutations have been found in low-grade serous ovarian cancer (LGSOC), 16 to $44 \%$ KRAS mutation and 2 to $20 \%$ BRAF mutation [51]. In studies investigating cervical cancer samples, KRAS mutations were identified as the second common oncogenic mutation following PIK3CA, although a prevalence of $2 \%$ makes it a rare event [52]. Nevertheless, KRAS mutations seem to be directly associated with type I estrogen-related endometrial cancer and its frequency is estimated to be $10-30 \%$ [53].

While genomic studies have shown that the KRAS pathway plays a key role in several gynecological cancers, the exact mechanism of tumorigenesis involving KRAS mutations has been mostly investigated in studies focusing on endometrial cancer and low-grade ovarian cancer. Mechanisms such as the upregulation of endometrial cell estrogen receptors through the KRAS pathway and hypermethylation-related changes in the KRAS promoter are well-demonstrated events in endometrial carcinogenesis [54,55]. KRAS mutations have been identified in early stage endometrial hyperplasia specimens [56] and due to their biological function to support tumor proliferation, by assessing the presence of this mutation may offer an opportunity to predict tumor invasiveness [57]. Similarly, KRAS mutation that range from 17 to $39.5 \%$ in ovarian serous borderline tumors, may represent early events in the tumorigenesis of the LGSOC [58]. In contrast, BRAF mutations with a frequency until $33 \%$ in ovarian serous borderline tumors, appear to have a less important role in the progression of low-grade serous ovarian cancer [58]. Taken together, these findings suggest that targeting KRAS pathway represents an exciting and promising new direction of therapy for gynecological cancers, including endometrial and LGSOC.

Several clinical trials from phase I to phase III targeting the KRAS pathway have been developed. Most treatment strategies act at the post-transcriptional level and target downstream effectors of KRAS, such as MEK1/2, a critical kinase in the mitogen-activated protein kinase signal transduction pathway. As observed in phase II trial investigating selumetinib in the treatment of recurrent or persistent endometrial cancer, single agent therapy in a non-selected population was unlikely to make a measurable difference in outcome [59]. More promising results were shown by a phase II trial investigating the 
same drug, selumetinib, in LGSOC [60]. The treatment was active in $15 \%$ of patients who showed a partial response. Additionally, 65\% of patients demonstrated clinical benefit by showing stable disease. On the basis of this positive trial, two large randomized clinical trials of MEK inhibitors in recurrent LGSOC were designed, evaluating the efficacy of two different MEK compared with standard of care treatments, including pegylated liposomal doxorubicin or weekly paclitaxel, topotecan, letrozole or tamoxifen. Only one of the trials met its primary endpoint, showing a clinical advantage of trametinib (HR, 0.48; $p<0.001$ ) (Clinicaltrials.gov Identifier: NCT02101788 (accessed on 24 February 2021)). A correlation between KRAS / BRAF mutations and clinical outcome analysis is ongoing. This mutational analysis will be very important, given the fact that integrated biomarkerbased trials represent the most likely strategy to fully realize the potential therapeutic efficacy of targeted therapy in gynecological cancer with less frequency of alterations in the KRAS pathway.

\section{Lung Cancer}

Lung cancers account for the highest cancer incidence rates behind gender specific cancers, such as prostate or breast cancers, as well as contribute to the greatest number of cancer-related deaths. Non-small cell lung cancer (NSCLC) is the most common type of lung cancer accounting for about $85 \%$ of all lung cancer cases and KRAS mutations are the most frequent alteration in these cancers [61]. More specifically, mutations in KRAS are present in up to $40 \%$ of lung adenocarcinomas [61]. Multiple oncogenic events have been of focus in NSCLC, including proteins upstream of KRAS, such as EGFR, as well as downstream effector proteins, such as BRAF [62]. Inhibitors and therapeutic strategies against these proteins, as well as others involved in various pathways have been developed and are showing promising results for the future [62]. However, as with most therapies used for NSCLC, the risk of resistance is high due to increased chances of compensatory mechanisms that evolve with time. Thus, identifying strategies to inhibit key players, such as $K R A S$, in this cancer type are necessary for novel alternatives.

Over the last few years, breakthroughs have been made in identifying novel strategies to target $K R A S$ and lung cancer has been a primary model of study to determine the effectiveness of these new agents. The compound AMG 510 (sotorasib), developed by Amgen, uses an irreversible occupation of the His95 groove near the cysteine pocket to inactivate KRAS [46]. This compound is an improved version derived from the covalent compound ARS-1620 [63]. AMG 510 significantly inhibits KRAS G12C and MAPK signaling in lung cancer cell lines but does not seem to influence wild-type KRAS. Initial results from a phase I/phase II clinical trial consisting of 533 patients with advanced NSCLC harboring KRAS G12C mutations as well as other solid tumors with KRAS G12C mutations has revealed that AMG 510 exerts a partial response in over 50\% and a full response in $46 \%$ of the patients studied. This is an ongoing trial with a completion date set for spring of 2024 (Clinicaltrials.gov Identifier: NCT03600883 (accessed on 24 February 2021)). Overall, AMG 510 shows encouraging anticancer activity with minimal toxicity in patients that were previously treated for advanced solid tumors harboring KRAS G12C mutations [10]. However, KRAS G12C signaling has been shown to be briefly suppressed by inhibitors and after a short time, re-accumulation of active KRAS and ERK signaling occurs. New $K R A S$ G12C can be produced is remains active and insensitive to drugs, resulting in a population of cells that do not respond to treatment [64]. This reactivation occurs through compensatory activation of receptor tyrosine kinases and SOS1/2 [65]. Future strategies must consider blocking new KRAS through these compensatory mechanisms and some new strategies are discussed below.

Other inhibitors against KRAS have been identified over the last couple of years that show promising results in lung cancer. The pyrazolopryimidine-based inhibitor Compound 11 has a high affinity to the allosteric p1 pocket of KRAS [66] and has shown disruption of MAPK signaling. The novel Mirati Therapeutics (San Diego, CA, USA) compound MRTX849 is currently in clinical trials as a KRAS G12C inhibitor and contains a similar 
structure to AMG 510. MRTX849 was shown to be an effective monotherapy in lung cancer cells lines and KRAS mutant lines showed to be more sensitive than wild-type cell lines. In an ongoing trial, patients with advanced lung cancer have shown a partial response when treated with MRTX849 and this trial is to be completed by the end of 2021 (Clinicaltrials.gov Identifier: NCT03785249 (accessed on 24 February 2021)). The KRAS G12C inhibitor known as JNJ-74699157 is currently being tested in a phase I clinical trial to determine the tolerated dose in patients with advanced solid tumors, including lung cancer (Clinicaltrials.gov Identifier: NCT04006301 (accessed on 24 February 2021)).

Another inhibitor currently being tested in patients and that will be completed in 2023 is the KRAS-SOS1 inhibitor BI 1701963 that is being analyzed as a monotherapy as well as with the MEK inhibitor trametinib to evaluate the maximum tolerated dose, safety and efficacy (Clinicaltrials.gov Identifier: NCT04111458 (accessed on 24 February 2021)). TVB-2640, a selective and reversible inhibitor of fatty acid synthase (FASN) that exerts effects on KRAS mutant versus KRAS wild-type NSCLCs, is currently being tested in a phase 2 study that includes NSCLC patients harboring KRAS mutations since KRAS mutant cases are associated with lipogenic features (Clinicaltrials.gov Identifier: NCT03808558 (accessed on 24 February 2021)). Lastly, the mRNA-5671 cancer vaccine for KRAS G12C, G12D, G13D and G12V is currently being tested in a phase I study as a monotherapy as well as with the PD1 inhibitor pembrolizumab in advanced or metastatic KRAS mutant NSCLC, colorectal and pancreatic cancer patients with an estimated study completion date being end of 2026 (Clinicaltrials.gov Identifier: NCT03948763 (accessed on 24 February 2021)) [4].

The fibroblast growth factor 1 (FGFR-1) inhibitor ponatinib is currently being tested in combination with trametinib in KRAS mutant NSCLC patients since it is known that this combination induces cell death in KRAS mutant positive tumors in vivo [67] (Clinicaltrials. gov Identifier: NCT03704688 (accessed on 24 February 2021)). In addition, trametinib is being tested in combination with the chemotherapeutic docetaxel in patients with recurrent or Stage IV KRAS mutant NSCLC (Clinicaltrials.gov Identifier: NCT02642042 (accessed on 24 February 2021)). In addition, there are various potential KRAS inhibitors in the preclinical stage that are currently being studies and may result in some strong leads in the near future [4]. Various other alternatives targeting KRAS indirectly through protein degradation pathways are also attractive strategies for the future [68,69].

\section{Pancreatic Cancer}

KRAS mutations are found in $90 \%$ of pancreatic ductal adenocarcinomas (PDACs) and are known to be an initiating event for this aggressive cancer type [46]. In the past, various approaches were studied to indirectly target KRAS in PDAC. Some of these techniques included targeting small GTPase effectors, such as the RACGEF-RAC1 and RACGEF-RAL pathways or focusing on targeting the mTOR or RAF/MEK/ERK signaling pathways [46]. In fact, various BRAF and MEK1/2 inhibitors are under clinical investigation and a handful have been improved for use in $B R A F$-mutant melanoma [46]. However, inhibitors of KRAS downstream effectors have not shown to be sufficient for the treatment of PDAC patients. A randomized phase II trial comparing the MEK inhibitor selumetinib and the AKT inhibitor MK-2206 to the chemotherapeutic FOLFIRINOX for metastatic PDAC patients showed inferior efficacy and increased adverse reactions [70]. A phase II study investigating REOLYSIN in combination with gemcitabine for chemotherapy naïve patients with advanced pancreatic adenocarcinoma showed a favorable response and will be tested in the future with anti-PDL1 therapies [71]. An ongoing trial being conducted by M.D. Anderson Cancer Center is testing the autophagy inhibitor hydroxychloroquine along with the MEK inhibitor binimetinib for the treatment of patients with KRAS mutant metastatic pancreatic cancer (Clinicaltrials.gov Identifier: NCT04132505 (accessed on 24 February 2021)). Selumetinib sulfate is also being tested in patients with locally advanced or metastatic pancreatic cancer harboring KRAS G12R mutations (Clinicaltrials.gov Identifier: NCT03040986 (accessed on 24 February 2021)). 
Evaluation of AMG 510 for the treatment of PDAC revealed significant inhibition of KRAS G12C and MAPK signaling in PDAC cell lines, with no effect on wild-type KRAS. As mentioned, AMG 510 is currently being tested in a larger trial and is showing to have promising results, but its effects on PDAC may be limited since the KRAS G12C mutation only occurs in 2\% of PDAC cases [46]. Similarly, MRTX849 has shown promising effects in PDAC cell lines and it will be interesting to see how it influences the treatment of PDAC patients [72]. Lastly, some studies have shown a synergistic response between KRAS and autophagy inhibitors in PDAC models [73]. These may provide novel strategies for the treatment of PDAC moving forward.

\section{Prostate Cancer}

Prostate cancer is the most common tumor and the second cause of cancer-related deaths in males. Mutations in KRAS account for $7 \%$ of prostate cancer cases and have been linked to effector proteins such as RAF, PI3K and GDP/GTP Ral exchange factor, contributing to downstream signaling responses. Mutant KRAS is known to be a transformative factor in prostate cancer and found to promote cancer stemness and bone metastasis [74-76]. In addition, KRAS rearrangements have been shown to promote the metastatic progression of prostate cancer [77].

Similar to what has been described for blood cancers, there are no therapies directly targeting KRAS in prostate cancer, but other proteins upstream and downstream of KRAS have attracted interest as potential targets. Targeting EGFR with inhibitors such as gefitinib, lapatinib and erlotinib has shown limited effectiveness in prostate cancer and more recent studies reveal that the extracellular release of EGFR through exosomes may be the culprit $[78,79]$. A recent study revealed that hyperactive ERK1 is present in a large number of refractory prostate cancer cases and these cases also have frequent amplifications in the MAPK pathway, suggesting that MEK/ERK can be pharmacologically targeted to treat refractory metastatic prostate cancer [80]. Future clinical trials will confirm whether targeting MEK/ERK in KRAS mutant cancers will be effective in the treatment of prostate cancer.

\section{Skin Cancer}

In melanoma, mutations in KRAS are rare, only accounting for $1.7 \%$ of cases [81]. However, mutations in $B R A F$ are prominent and inhibition of BRAF is a common, standard therapy for the treatment of $B R A F$-mutant melanoma. Unfortunately, only $50 \%$ of patients containing $B R A F$ mutations respond to therapy and there are only slight improvements in overall survival. Recent work has shown that inhibition of wild-type KRAS in BRAFmutant melanoma can be a potential strategy since inhibition of $K R A S$ works synergistically with BRAF inhibition to reduce the proliferation and induce apoptosis independent of $B R A F$ mutation status [82]. Similar to melanoma, KRAS is found to be mutated in skin squamous cell carcinoma but at a low rate. In fact, many mouse models of cutaneous squamous cell carcinoma take advantage of inducible mutations in KRAS along with mutations of specific tumor suppressor genes [83]. There has been a great deal of progress in targeting downstream effector proteins of KRAS for the treatment of melanoma. For example, there are two BRAF inhibitors, including vemurafenib and dabrafenib, as well as the two MEK1/2 inhibitors trametinib and cobimetinib, that have been approved for BRAFmutant melanoma [46]. This is one example of a success story of targeting downstream effectors of KRAS for cancer therapy.

\section{Conclusions and Future Directions}

Dysregulation of the MAPK pathway plays a central role in a number of malignancies and therapeutic inhibition of oncogenic RAS is of great clinical importance. There has been a significant progress made in this area resulting in successful targeting of KRAS or downstream effectors in several cancer types, with multiple agents in clinical trials (Table 1). The trials listed in Table 1 are only a handful of selected studies chosen to be highlighted in this review. It is important to note that over 200 results exist when searching 
for clinical trials related to KRAS on Clinicaltrials.gov (accessed on 24 February 2021). A good number of these trials are recruiting and active as well are testing combinations between chemotherapeutics and other drugs that have been shown to attenuate KRAS mutant phenotypes in vitro. However, our understanding how KRAS inhibitory ligands selectively target protein conformation and how they interfere with the MAPK pathway is most likely still incomplete. In addition, we need to fully understand why acquired KRAS mutations are more prominent in certain cancer types. For example, KRAS mutations in lung cancer may be more frequent due to exposure to carcinogens, such as tobacco smoke. Overall, the close interaction between preclinical experimental approaches and theoretical approaches, including molecular dynamic simulation, will continue to play a key role in the treatment and the ultimate eradication of KRAS mutant tumors.

Table 1. Select recent clinical trials targeting KRAS and downstream signaling pathways.

\begin{tabular}{|c|c|c|c|c|}
\hline Trial ID & Trial Title & Target(s) & Cancer(s) & Mechanism \\
\hline NCT01274624 & $\begin{array}{l}\text { Study of REOLYSIN in } \\
\text { Combination With } \\
\text { FOLFIRI and Bevacizumab } \\
\text { in FOLFIRI Naïve Patients } \\
\text { With KRAS Mutant } \\
\text { Metastatic Colorectal } \\
\text { Cancer }\end{array}$ & Activated RAS & CRC & $\begin{array}{l}\text { Stimulates lysis of tumor } \\
\text { cells and induces } \\
\text { antitumor immunity }\end{array}$ \\
\hline NCT03808558 & $\begin{array}{l}\text { Phase } 2 \text { Study of TVB-2640 } \\
\text { in KRAS Non-Small Cell } \\
\text { Lung Carcinomas }\end{array}$ & FASN & NSCLC & $\begin{array}{l}\text { Disrupts tumor lipid rafts } \\
\text { and RAS localization }\end{array}$ \\
\hline NCT03600883 & $\begin{array}{l}\text { A Phase } 1 / 2, \text { Study } \\
\text { Evaluating the Safety, } \\
\text { Tolerability, PK, and } \\
\text { Efficacy of AMG } 510 \text { in } \\
\text { Subjects With Solid Tumors } \\
\text { With a Specific KRAS } \\
\text { Mutation (CodeBreak 100) }\end{array}$ & KRAS G12C & NSCLC, solid tumors & $\begin{array}{l}\text { Binds to cysteine residue in } \\
\text { KRAS G12C mutations } \\
\text { holding protein in inactive } \\
\text { form and prevents } \\
\text { downstream signaling }\end{array}$ \\
\hline NCT03785249 & $\begin{array}{l}\text { Phase } 1 / 2 \text { Study of } \\
\text { MRTX849 in Patients With } \\
\text { Cancer Having a KRAS } \\
\text { G12C Mutation } \\
\text { KRYSTAL-1 }\end{array}$ & KRAS G12C & $\begin{array}{l}\text { NSCLC, CRC, other } \\
\text { solid tumors }\end{array}$ & $\begin{array}{l}\text { Modifies mutant cysteine } \\
12 \text { in a GDP-bound state } \\
\text { and inhibits KRAS } \\
\text { dependent signaling }\end{array}$ \\
\hline NCT04006301 & $\begin{array}{l}\text { First-in-Human Study of } \\
\text { JNJ-74699157 in } \\
\text { Participants With Tumors } \\
\text { Harboring the KRAS G12C } \\
\text { Mutation }\end{array}$ & KRAS G12C & NSCLC, solid tumors & $\begin{array}{l}\text { Binds to KRAS G23C and } \\
\text { holds the protein in } \\
\text { inactive form, preventing } \\
\text { downstream signaling }\end{array}$ \\
\hline NCT03948763 & $\begin{array}{l}\text { A Study of } \\
\text { mRNA-5671/V941 as } \\
\text { Monotherapy and in } \\
\text { Combination With } \\
\text { Pembrolizumab (V941-001) }\end{array}$ & $\begin{array}{l}\text { KRAS G12D, G12V, } \\
\text { G13D, and G12C }\end{array}$ & $\begin{array}{l}\text { NSCLC, CRC, } \\
\text { pancreatic }\end{array}$ & $\begin{array}{l}\text { Induces T-cell dependent } \\
\text { immune responses to } \\
\text { destroy tumors presenting } \\
\text { KRAS mutations }\end{array}$ \\
\hline NCT04132505 & $\begin{array}{l}\text { Binimetinib and } \\
\text { Hydroxychloroquine in } \\
\text { Treating Patients With } \\
\text { KRAS Mutant Metastatic } \\
\text { Pancreatic Cancer }\end{array}$ & MEK, Autophagy & pancreatic & $\begin{array}{l}\text { Binimetinib: } \\
\text { Noncompetitive ATP } \\
\text { inhibitor preventing MEK } \\
\text { signaling. } \\
\text { Hydroxychloroquine: } \\
\text { Inhibits autophagy to } \\
\text { avoid metabolism of } \\
\text { Binimetinib }\end{array}$ \\
\hline
\end{tabular}


Table 1. Cont.

\begin{tabular}{|c|c|c|c|c|}
\hline Trial ID & Trial Title & Target(s) & Cancer(s) & Mechanism \\
\hline NCT03040986 & $\begin{array}{l}\text { Selumetinib Sulfate in } \\
\text { Treating Patients With } \\
\text { Locally Advanced or } \\
\text { Metastatic Pancreatic } \\
\text { Cancer With KRAS G12R } \\
\text { Mutations }\end{array}$ & MEK & pancreatic & $\begin{array}{l}\text { Potent and selective } \\
\text { inhibitor against MEK1/2 } \\
\text { and KRAS dependent } \\
\text { signaling }\end{array}$ \\
\hline NCT02642042 & $\begin{array}{l}\text { Trametinib and Docetaxel } \\
\text { in Treating Patients With } \\
\text { Recurrent or Stage IV } \\
\text { KRAS Mutation Positive } \\
\text { Non-small Cell Lung } \\
\text { Cancer }\end{array}$ & MEK & NSCLC & $\begin{array}{l}\text { Trametinib: Inhibits MEK } \\
\text { signaling downstream of } \\
\text { KRAS. Docetaxel: } \\
\text { Chemotherapeutic }\end{array}$ \\
\hline NCT02101788 & $\begin{array}{l}\text { Trametinib in Treating } \\
\text { Patients With Recurrent or } \\
\text { Progressive Low-Grade } \\
\text { Ovarian Cancer or } \\
\text { Peritoneal Cavity Cancer }\end{array}$ & MEK & ovarian, peritoneal & $\begin{array}{l}\text { Inhibits MEK signaling } \\
\text { downstream of KRAS }\end{array}$ \\
\hline NCT02613650 & $\begin{array}{l}\text { A Trial of mFOLFIRI With } \\
\text { MEK162 in Patients With } \\
\text { Advanced RAS (HRAS, } \\
\text { NRAS, or KRAS) Positive } \\
\text { Metastatic Colorectal } \\
\text { Cancers }\end{array}$ & MEK & CRC & $\begin{array}{l}\text { MEK162: Uncompetitive } \\
\text { ATP inhibitor suppresses } \\
\text { the activity of MEK1/2 and } \\
\text { KRAS downstream } \\
\text { signaling. mFOLFIRI: } \\
\text { Chemotherapeutic }\end{array}$ \\
\hline NCT03704688 & $\begin{array}{l}\text { Trial of Trametinib and } \\
\text { Ponatinib in Patients With } \\
\text { KRAS Mutant Advanced } \\
\text { Non-Small Cell Lung } \\
\text { Cancer }\end{array}$ & $\begin{array}{l}\text { MEK, Multi-tyrosine } \\
\text { Kinase }\end{array}$ & NSCLC & $\begin{array}{l}\text { Trametinib: Inhibits MEK } \\
\text { signaling downstream of } \\
K R A S \text {. Ponatinib: Targets } \\
\text { multiple tyrosine kinases } \\
\text { and inhibits signaling }\end{array}$ \\
\hline NCT03829410 & $\begin{array}{l}\text { Onvansertib in } \\
\text { Combination With } \\
\text { FOLFIRI and Bevacizumab } \\
\text { for Second Line Treatment } \\
\text { of Metastatic Colorectal } \\
\text { Cancer Patients With a } \\
\text { KRAS Mutation }\end{array}$ & PLK1, VEGF & CRC & $\begin{array}{l}\text { Onvansertib: Selectively } \\
\text { inhibits PLK1 causing } \\
\text { mitotic arrest and cell } \\
\text { death. Bevacizumab: Binds } \\
\text { to VEGF and reduces blood } \\
\text { supply to tumors. FOLFIRI: } \\
\text { Chemotherapeutic }\end{array}$ \\
\hline NCT04111458 & $\begin{array}{l}\text { A Study to Test Different } \\
\text { Doses of BI } 1701963 \text { Alone } \\
\text { and Combined With } \\
\text { Trametinib in Patients With } \\
\text { Different Types of } \\
\text { Advanced Cancer (Solid } \\
\text { Tumours With KRAS } \\
\text { Mutation) }\end{array}$ & SOS1, MEK & NSCLC, solid tumors & $\begin{array}{l}\text { BI 1701963: Inhibits KRAS } \\
\text { binding to SOS1, leading to } \\
\text { KRAS inactivation. } \\
\text { Trametinib: Inhibits MEK } \\
\text { signaling downstream of } \\
\text { KRAS }\end{array}$ \\
\hline
\end{tabular}

Author Contributions: L.M.M., A.C.-R., L.S. and J.R. wrote the review. All authors have read and agreed to the published version of the manuscript.

Funding: L.M.M. received support by the Postdoctoral Fellowship 131779-PF-18-034-01-DMC from the American Cancer Society. L.S. received support from NKFIH-NNE-130913 and Bolyai Janos fellowship of the Hungarian Academy of Sciences.

Institutional Review Board Statement: Not applicable.

Informed Consent Statement: Not applicable.

Data Availability Statement: Not applicable. 
Conflicts of Interest: The authors declare no conflict of interest.

\section{References}

1. Simanshu, D.K.; Nissley, D.V.; McCormick, F. RAS Proteins and Their Regulators in Human Disease. Cell 2017, 170, 17-33. [CrossRef]

2. Saito, Y.; Koya, J.; Araki, M.; Kogure, Y.; Shingaki, S.; Tabata, M.; McClure, M.B.; Yoshifuji, K.; Matsumoto, S.; Isaka, Y.; et al. Landscape and function of multiple mutations within individual oncogenes. Nat. Cell Biol. 2020, 582, 95-99. [CrossRef]

3. Del Re, M.; Rofi, E.; Restante, G.; Crucitta, S.; Arrigoni, E.; Fogli, S.; Di Maio, M.; Petrini, I.; Danesi, R. Implications of KRAS mutations in acquired resistance to treatment in NSCLC. Oncotarget 2018, 9, 6630-6643. [CrossRef]

4. Mullard, A. Cracking KRAS. Nat. Rev. Drug Discov. 2019, 18, 887-891. [CrossRef] [PubMed]

5. Ward, A.F.; Braun, B.S.; Shannon, K.M. Targeting oncogenic Ras signaling in hematologic malignancies. Blood 2012, 120, $3397-3406$. [CrossRef] [PubMed]

6. Zhao, S.; Zhang, Y.; Sha, K.; Tang, Q.; Yang, X.; Yu, C.; Liu, Z.; Sun, W.; Cai, L.; Xu, C.; et al. KRAS (G12D) Cooperates with AML1/ETO to Initiate a Mouse Model Mimicking Human Acute Myeloid Leukemia. Cell. Physiol. Biochem. 2014, $33,78-87$. [CrossRef]

7. Zhou, J.-D.; Yao, D.-M.; Li, X.-X.; Zhang, T.-J.; Zhang, W.; Ma, J.-C.; Guo, H.; Deng, Z.-Q.; Lin, J.; Qian, J. KRAS overexpression independent of RAS mutations confers an adverse prognosis in cytogenetically normal acute myeloid leukemia. Oncotarget 2017, 8, 66087-66097. [CrossRef]

8. Vendramini, E.; Bomben, R.; Pozzo, F.; Benedetti, D.; Bittolo, T.; Rossi, F.M.; Bo, M.D.; Rabe, K.G.; Pozzato, G.; Zaja, F.; et al. KRAS, NRAS, and BRAF mutations are highly enriched in trisomy 12 chronic lymphocytic leukemia and are associated with shorter treatment-free survival. Leukemia 2019, 33, 2111-2115. [CrossRef] [PubMed]

9. Jerchel, I.S.; Hoogkamer, A.Q.; Ariës, I.M.; Steeghs, E.M.P.; Boer, J.M.; Besselink, N.J.M.; Boeree, A.; Van De Ven, C.; De GrootKruseman, A.H.; De Haas, V.; et al. RAS pathway mutations as a predictive biomarker for treatment adaptation in pediatric B-cell precursor acute lymphoblastic leukemia. Leukemia 2017, 32, 931-940. [CrossRef]

10. Hou, H.-A.; Tien, H.-F. Genomic landscape in acute myeloid leukemia and its implications in risk classification and targeted therapies. J. Biomed. Sci. 2020, 27, 1-13. [CrossRef] [PubMed]

11. Neubauer, A.; Maharry, K.; Mrózek, K.; Thiede, C.; Marcucci, G.; Paschka, P.; Mayer, R.J.; Larson, R.A.; Liu, E.T.; Bloomfield, C.D. Patients with Acute Myeloid Leukemia and RAS Mutations Benefit Most from Postremission High-Dose Cytarabine: A Cancer and Leukemia Group B Study. J. Clin. Oncol. 2008, 26, 4603-4609. [CrossRef] [PubMed]

12. Burgess, M.R.; Hwang, E.; Mroue, R.; Bielski, C.M.; Wandler, A.M.; Huang, B.J.; Firestone, A.J.; Young, A.; Lacap, J.A.; Crocker, L.; et al. KRAS Allelic Imbalance Enhances Fitness and Modulates MAP Kinase Dependence in Cancer. Cell 2017, 168, 817-829.e15. [CrossRef]

13. Weisberg, E.; Meng, C.; Case, A.; Sattler, M.; Tiv, H.L.; Gokhale, P.C.; Buhrlage, S.; Wang, J.; Gray, N.; Stone, R.; et al. Evaluation of ERK as a therapeutic target in acute myelogenous leukemia. Leukemia 2020, 34, 625-629. [CrossRef] [PubMed]

14. Steelman, L.S.; Franklin, R.A.; Abrams, S.L.; Chappell, W.; Kempf, C.R.; Bäsecke, J.; Stivala, F.; Donia, M.; Fagone, P.; Nicoletti, F.; et al. Roles of the Ras/Raf/MEK/ERK pathway in leukemia therapy. Leukemia 2011, 25, 1080-1094. [CrossRef] [PubMed]

15. Hofmann, M.H.; Gmachl, M.; Ramharter, J.; Savarese, F.; Gerlach, D.; Marszalek, J.R.; Sanderson, M.P.; Kessler, D.; Trapani, F.; Arnhof, H.; et al. BI-3406, a Potent and Selective SOS1-KRAS Interaction Inhibitor, Is Effective in KRAS-Driven Cancers through Combined MEK Inhibition. Cancer Discov. 2021, 11, 142-157. [CrossRef] [PubMed]

16. Cai, D.; Choi, P.S.; Gelbard, M.; Meyerson, M. Identification and Characterization of Oncogenic SOS1 Mutations in Lung Adenocarcinoma. Mol. Cancer Res. 2019, 17, 1002-1012. [CrossRef]

17. Koschut, D.; Ray, D.; Li, Z.; Giarin, E.; Groet, J.; Alić, I.; Kham, S.K.-Y.; Chng, W.J.; Ariffin, H.; Weinstock, D.M.; et al. RAS-protein activation but not mutation status is an outcome predictor and unifying therapeutic target for high-risk acute lymphoblastic leukemia. Oncogene 2021, 40, 746-762. [CrossRef]

18. Galiè, M. RAS as Supporting Actor in Breast Cancer. Front. Oncol. 2019, 9, 1199. [CrossRef] [PubMed]

19. Adnane, J.; Jackson, R.J.; Nicosia, S.V.; Cantor, A.B.; Pledger, W.J.; Sebti, S.M. Loss of p21WAF1/CIP1 accelerates Ras oncogenesis in a transgenic/knockout mammary cancer model. Oncogene 2000, 19, 5338-5347. [CrossRef]

20. Ricoult, S.J.H.; Yecies, J.L.; Ben-Sahra, I.; Manning, B.D. Oncogenic PI3K and K-Ras stimulate de novo lipid synthesis through mTORC1 and SREBP. Oncogene 2016, 35, 1250-1260. [CrossRef]

21. Sorlie, T.; Perou, C.M.; Tibshirani, R.; Aas, T.; Geisler, S.; Johnsen, H.; Hastie, T.; Eisen, M.B.; van de Rijn, M.; Jeffrey, S.S.; et al. Gene expression patterns of breast carcinomas distinguish tumor subclasses with clinical implications. Proc. Natl. Acad. Sci. USA 2001, 98, 10869-10874. [CrossRef] [PubMed]

22. Perou, C.M.; Sørlie, T.; Eisen, M.B.; Van De Rijn, M.; Jeffrey, S.S.; Rees, C.A.; Pollack, J.R.; Ross, D.T.; Johnsen, H.; Akslen, L.A.; et al. Molecular portraits of human breast tumours. Nature 2000, 406, 747-752. [CrossRef] [PubMed]

23. Ho, J.-Y.; Hsu, R.-J.; Liu, J.-M.; Chen, S.-C.; Liao, G.-S.; Gao, H.-W.; Yu, C.-P. MicroRNA-382-5p aggravates breast cancer progression by regulating the RERG/Ras/ERK signaling axis. Oncotarget 2017, 8, 22443-22459. [CrossRef] [PubMed]

24. Yu, Y.; Hao, Y.; Feig, L.A. The R-Ras GTPase Mediates Cross Talk between Estrogen and Insulin Signaling in Breast Cancer Cells. Mol. Cell. Biol. 2006, 26, 6372-6380. [CrossRef] 
25. Feng, M.; Bao, Y.; Li, Z.; Li, J.; Gong, M.; Lam, S.; Wang, J.; Marzese, D.M.; Donovan, N.; Tan, E.Y.; et al. RASAL2 activates RAC1 to promote triple-negative breast cancer progression. J. Clin. Investig. 2014, 124, 5291-5304. [CrossRef] [PubMed]

26. Nguyen, L.V.; Pellacani, D.; Lefort, S.; Kannan, N.; Osako, T.; Makarem, M.; Cox, C.L.; Kennedy, W.; Beer, P.A.; Carles, A.; et al. Barcoding reveals complex clonal dynamics of de novo transformed human mammary cells. Nat. Cell Biol. 2015, 528, $267-271$. [CrossRef]

27. Loi, S.; Dushyanthen, S.S.; Beavis, P.P.; Salgado, R.; Denkert, C.; Savas, P.P.; Combs, S.S.; Rimm, D.D.; Giltnane, J.J.; Estrada, M.V.M.; et al. RAS/MAPK Activation Is Associated with Reduced Tumor-Infiltrating Lymphocytes in Triple-Negative Breast Cancer: Therapeutic Cooperation Between MEK and PD-1/PD-L1 Immune Checkpoint Inhibitors. Clin. Cancer Res. 2016, 22, 1499-1509. [CrossRef]

28. Adeyinka, A.; Nui, Y.; Cherlet, T.; Snell, L.; Watson, P.H.; Murphy, L.C. Activated mitogen-activated protein kinase expression during human breast tumorigenesis and breast cancer progression. Clin. Cancer Res. 2002, 8, 1747-1753. [PubMed]

29. Hoeflich, K.P.; O’Brien, C.; Boyd, Z.; Cavet, G.; Guerrero, S.; Jung, K.; Januario, T.; Savage, H.; Punnoose, E.; Truong, T.; et al. In vivo Antitumor Activity of MEK and Phosphatidylinositol 3-Kinase Inhibitors in Basal-Like Breast Cancer Models. Clin. Cancer Res. 2009, 15, 4649-4664. [CrossRef]

30. Zhao, Y.; Ge, C.C.; Wang, J.; Wu, X.X.; Li, X.M.; Li, W.; Wang, S.S.; Liu, T.; Hou, J.Z.; Sun, H.; et al. MEK inhibitor, PD98059, promotes breast cancer cell migration by inducing beta-catenin nuclear accumulation. Oncol. Rep. 2017, 38, 3055-3063. [CrossRef]

31. Di Simone, D.; Galimberti, S.; Basolo, F.; Ciardiello, F.; Petrini, M.; Scheper, R.J. c-Ha-ras transfection and expression of MDRrelated genes in MCF-10A human breast cell line. Anticancer Res. 1997, 17, 3587-3592.

32. Zoppoli, G.; Moran, E.; Soncini, D.; Cea, M.; Garuti, A.; Rocco, I.; Cirmena, G.; Grillo, V.; Bagnasco, L.; Icardi, G.; et al. Ras-induced resistance to lapatinib is overcome by MEK inhibition. Curr. Cancer Drug Targets 2010, 10, 168-175. [CrossRef] [PubMed]

33. McGlynn, L.M.; Kirkegaard, T.; Edwards, J.; Tovey, S.; Cameron, D.; Twelves, C.; Bartlett, J.M.; Cooke, T.G. Ras/Raf-1/MAPK Pathway Mediates Response to Tamoxifen but not Chemotherapy in Breast Cancer Patients. Clin. Cancer Res. 2009, 15, 1487-1495. [CrossRef] [PubMed]

34. Porru, M.; Pompili, L.; Caruso, C.; Biroccio, A.; Leonetti, C. Targeting KRAS in metastatic colorectal cancer: Current strategies and emerging opportunities. J. Exp. Clin. Cancer Res. 2018, 37, 1-10. [CrossRef] [PubMed]

35. Van Cutsem, E.; Cervantes, A.; Adam, R.; Sobrero, A.; Van Krieken, J.H.; Aderka, D.; Aguilar, E.A.; Bardelli, A.; Benson, A.; Bodoky, G.; et al. ESMO consensus guidelines for the management of patients with metastatic colorectal cancer. Ann. Oncol. 2016, 27, 1386-1422. [CrossRef] [PubMed]

36. Parseghian, C.; Loree, J.; Morris, V.; Liu, X.; Clifton, K.; Napolitano, S.; Henry, J.; Pereira, A.; Vilar, E.; Johnson, B.; et al. AntiEGFR-resistant clones decay exponentially after progression: Implications for anti-EGFR re-challenge. Ann. Oncol. 2019, 30, 243-249. [CrossRef]

37. Siravegna, G.; Bardelli, A. Failure is not final: ctDNA-guided rechallenge therapy in colorectal cancer. Ann. Oncol. 2019, 30 , 1671. [CrossRef] [PubMed]

38. Allegra, C.J.; Jessup, J.M.; Somerfield, M.R.; Hamilton, S.R.; Hammond, E.H.; Hayes, D.F.; McAllister, P.K.; Morton, R.F.; Schilsky, R.L. American Society of Clinical Oncology Provisional Clinical Opinion: Testing for KRAS Gene Mutations in Patients with Metastatic Colorectal Carcinoma to Predict Response to Anti-Epidermal Growth Factor Receptor Monoclonal Antibody Therapy. J. Clin. Oncol. 2009, 27, 2091-2096. [CrossRef]

39. Karnoub, A.E.; Weinberg, R.A. Ras oncogenes: Split personalities. Nat. Rev. Mol. Cell Biol. 2008, 9, 517-531. [CrossRef] [PubMed]

40. Papke, B.; Murarka, S.; Vogel, H.A.; Martin-Gago, P.; Kovacevic, M.; Truxius, D.C.; Fansa, E.K.; Ismail, S.; Zimmermann, G.; Heinelt, K.; et al. Identification of pyrazolopyridazinones as PDEdelta inhibitors. Nat. Commun. 2016, 7, 11360. [CrossRef]

41. Porru, M.; Artuso, S.; Salvati, E.; Bianco, A.; Franceschin, M.; Diodoro, M.G.; Passeri, D.; Orlandi, A.; Savorani, F.; D’Incalci, M.; et al. Targeting G-Quadruplex DNA Structures by EMICORON Has a Strong Antitumor Efficacy against Advanced Models of Human Colon Cancer. Mol. Cancer Ther. 2015, 14, 2541-2551. [CrossRef] [PubMed]

42. Shima, F.; Yoshikawa, Y.; Ye, M.; Araki, M.; Matsumoto, S.; Liao, J.; Hu, L.; Sugimoto, T.; Ijiri, Y.; Takeda, A.; et al. In silico discovery of small-molecule Ras inhibitors that display antitumor activity by blocking the Ras-effector interaction. Proc. Natl. Acad. Sci. USA 2013, 110, 8182-8187. [CrossRef]

43. Hiraoka, K.; Inoue, T.; Taylor, R.D.; Watanabe, T.; Koshikawa, N.; Yoda, H.; Shinohara, K.-I.; Takatori, A.; Sugimoto, H.; Maru, Y.; et al. Inhibition of KRAS codon 12 mutants using a novel DNA-alkylating pyrrole-imidazole polyamide conjugate. Nat. Commun. 2015, 6, 6706. [CrossRef]

44. Tutuka, C.S.A.; Andrews, M.C.; Mariadason, J.M.; Ioannidis, P.; Hudson, C.; Cebon, J.; Behren, A. PLX8394, a new generation BRAF inhibitor, selectively inhibits BRAF in colonic adenocarcinoma cells and prevents paradoxical MAPK pathway activation. Mol. Cancer 2017, 16, 112. [CrossRef] [PubMed]

45. Chen, X.; Guo, X.; Zhang, H.; Xiang, Y.; Chen, J.; Yin, Y.; Cai, X.; Wang, K.; Wang, G.; Ba, Y.; et al. Role of miR-143 targeting KRAS in colorectal tumorigenesis. Oncogene 2009, 28, 1385-1392. [CrossRef]

46. Gillson, J.; Ramaswamy, Y.; Singh, G.; Gorfe, A.A.; Pavlakis, N.; Samra, J.; Mittal, A.; Sahni, S. Small Molecule KRAS Inhibitors: The Future for Targeted Pancreatic Cancer Therapy? Cancers 2020, 12, 1341. [CrossRef]

47. Samalin, E.; Bouché, O.; Thézénas, S.; François, E.; Adenis, A.; Bennouna, J.; Taieb, J.; Desseigne, F.; Seitz, J.F.; Conroy, T.; et al. Sorafenib and irinotecan (NEXIRI) as second- or later-line treatment for patients with metastatic colorectal cancer and KRAS-mutated tumours: A multicentre Phase I/II trial. Br. J. Cancer 2014, 110, 1148-1154. [CrossRef] 
48. Samalin, E.; de la Fouchardière, C.; Thézenas, S.; Boige, V.; Senellart, H.; Guimbaud, R.; Taïeb, J.; François, E.; Galais, M.-P.; Lièvre, A.; et al. Sorafenib Plus Irinotecan Combination in Patients with RAS-mutated Metastatic Colorectal Cancer Refractory to Standard Combined Chemotherapies: A Multicenter, Randomized Phase 2 Trial (NEXIRI-2/PRODIGE 27). Clin. Colorectal Cancer 2020, 19, 301-310.e1. [CrossRef]

49. Torre, L.A.; Islami, F.; Siegel, R.L.; Ward, E.M.; Jemal, A. Global Cancer in Women: Burden and Trends. Cancer Epidemiol. Biomark. Prev. 2017, 26, 444-457. [CrossRef]

50. Spaans, V.M.; Trietsch, M.D.; Crobach, S.; Stelloo, E.; Kremer, D.; Osse, E.M.; Haar, N.T.T.; Van Eijk, R.; Muller, S.; Van Wezel, T.; et al. Designing a High-Throughput Somatic Mutation Profiling Panel Specifically for Gynaecological Cancers. PLoS ONE 2014, 9 , e93451. [CrossRef]

51. Kurman, R.J.; Shih Ie, M. Pathogenesis of ovarian cancer: Lessons from morphology and molecular biology and their clinical implications. Int. J. Gynecol. Pathol. 2008, 27, 151-160. [CrossRef] [PubMed]

52. Jiang, W.; Xiang, L.; Pei, X.; He, T.; Shen, X.; Wu, X.; Yang, H. Mutational analysis of KRAS and its clinical implications in cervical cancer patients. J. Gynecol. Oncol. 2018, 29, e4. [CrossRef]

53. Sideris, M.; Emin, E.I.; Abdullah, Z.; Hanrahan, J.; Stefatou, K.M.; Sevas, V.; Emin, E.; Hollingworth, T.; Odejinmi, F.; Papagrigoriadis, S.; et al. The Role of KRAS in Endometrial Cancer: A Mini-Review. Anticancer Res. 2019, 39, 533-539. [CrossRef]

54. Ring, K.L.; Yates, M.S.; Schmandt, R.; Onstad, M.; Zhang, Q.; Celestino, J.; Kwan, S.-Y.; Lu, K.H. Endometrial Cancers with Activating KRas Mutations Have Activated Estrogen Signaling and Paradoxical Response to MEK Inhibition. Int. J. Gynecol. Cancer 2017, 27, 854-862. [CrossRef] [PubMed]

55. Peterson, L.M.; Kipp, B.R.; Halling, K.C.; Kerr, S.E.; Smith, D.I.; Distad, T.J.; Clayton, A.C.; Medeiros, F. Molecular characterization of endometrial cancer: A correlative study assessing microsatellite instability, MLH1 hypermethylation, DNA mismatch repair protein expression, and PTEN, PIK3CA, KRAS, and BRAF mutation analysis. Int. J. Gynecol. Pathol. 2012, 31, 195-205. [CrossRef]

56. Sasaki, H.; Nishii, H.; Takahashi, H.; Tada, A.; Furusato, M.; Terashima, Y.; Siegal, G.P.; Parker, S.L.; Kohler, M.F.; Berchuck, A. Mutation of the Ki-ras protooncogene in human endometrial hyperplasia and carcinoma. Cancer Res. 1993, 53, 1906-1910. [PubMed]

57. Tsuda, H.; Jiko, K.; Yajima, M.; Yamada, T.; Tanemura, K.; Tsunematsu, R.; Ohmi, K.; Sonoda, T.; Hirohashi, S. Frequent Occurrence of c-Ki-ras Gene Mutations in Well Differentiated Endometrial Adenocarcinoma Showing Infiltrative Local Growth with Fibrosing Stromal Response. Int. J. Gynecol. Pathol. 1995, 14, 255-259. [CrossRef]

58. Malpica, A.; Wong, K.-K. The molecular pathology of ovarian serous borderline tumors. Ann. Oncol. 2016,27 (Suppl. 1), i16-i19. [CrossRef] [PubMed]

59. Coleman, R.L.; Sill, M.W.; Thaker, P.H.; Bender, D.P.; Street, D.; McGuire, W.P.; Johnston, C.M.; Rotmensch, J. A phase II evaluation of selumetinib (AZD6244, ARRY-142886), a selective MEK-1/2 inhibitor in the treatment of recurrent or persistent endometrial cancer: An NRG Oncology/Gynecologic Oncology Group study. Gynecol. Oncol. 2015, 138, 30-35. [CrossRef]

60. Farley, J.; Brady, W.E.; Vathipadiekal, V.; Lankes, H.A.; Coleman, R.; Morgan, M.A.; Mannel, R.; Yamada, S.D.; Mutch, D.; Rodgers, W.H.; et al. Selumetinib in women with recurrent low-grade serous carcinoma of the ovary or peritoneum: An open-label, single-arm, phase 2 study. Lancet Oncol. 2013, 14, 134-140. [CrossRef]

61. Adderley, H.; Blackhall, F.H.; Lindsay, C.R. KRAS-mutant non-small cell lung cancer: Converging small molecules and immune checkpoint inhibition. EBioMedicine 2019, 41, 711-716. [CrossRef]

62. Mustachio, L.M.; Roszik, J. Current Targeted Therapies for the Fight against Non-Small Cell Lung Cancer. Pharmaceuticals 2020, 13, 374. [CrossRef]

63. Janes, M.R.; Zhang, J.; Li, L.-S.; Hansen, R.; Peters, U.; Guo, X.; Chen, Y.; Babbar, A.; Firdaus, S.J.; Darjania, L.; et al. Targeting KRAS Mutant Cancers with a Covalent G12C-Specific Inhibitor. Cell 2018, 172, 578-589.e17. [CrossRef] [PubMed]

64. Xue, J.Y.; Zhao, Y.; Aronowitz, J.; Mai, T.T.; Vides, A.; Qeriqi, B.; Kim, D.; Li, C.; De Stanchina, E.; Mazutis, L.; et al. Rapid non-uniform adaptation to conformation-specific KRAS(G12C) inhibition. Nat. Cell Biol. 2020, 577, 421-425. [CrossRef] [PubMed]

65. Kim, D.; Xue, J.Y.; Lito, P. Targeting KRAS(G12C): From Inhibitory Mechanism to Modulation of Antitumor Effects in Patients. Cell 2020, 183, 850-859. [CrossRef]

66. McCarthy, M.J.; Pagba, C.V.; Prakash, P.; Naji, A.K.; Van Der Hoeven, D.; Liang, H.; Gupta, A.K.; Zhou, Y.; Cho, K.-J.; Hancock, J.F.; et al. Discovery of High-Affinity Noncovalent Allosteric KRAS Inhibitors That Disrupt Effector Binding. ACS Omega 2019, 4, 2921-2930. [CrossRef] [PubMed]

67. Manchado, E.; Weissmueller, S.; Morris, J.P.; Chen, C.-C.; Wullenkord, R.; Lujambio, A.; De Stanchina, E.; Poirier, J.T.; Gainor, J.F.; Corcoran, R.B.; et al. A combinatorial strategy for treating KRAS-mutant lung cancer. Nat. Cell Biol. 2016, 534, 647-651. [CrossRef]

68. Röth, S.; Macartney, T.J.; Konopacka, A.; Queisser, M.A.; Sapkota, G. Targeting Endogenous K-RAS for Degradation Through the Affinity-Directed Protein Missile System. Cell. Chem. Biol. 2019, 27, 1151-1163.e6. [CrossRef]

69. Mustachio, L.M.; Lu, Y.; Tafe, L.J.; Memoli, V.; Rodriguez-Canales, J.; Mino, B.; Villalobos, P.A.; Wistuba, I.; Katayama, H.; Hanash, S.M.; et al. Deubiquitinase USP18 Loss Mislocalizes and Destabilizes KRAS in Lung Cancer. Mol. Cancer Res. 2017, 15, 905-914. [CrossRef] [PubMed]

70. Chung, V.; McDonough, S.; Philip, P.A.; Cardin, D.; Wang-Gillam, A.; Hui, L.; Tejani, M.A.; Seery, T.E.; Dy, I.A.; Al Baghdadi, T.; et al. Effect of Selumetinib and MK-2206 vs Oxaliplatin and Fluorouracil in Patients with Metastatic Pancreatic Cancer After Prior Therapy: SWOG $S 1115$ Study Randomized Clinical Trial. JAMA Oncol. 2017, 3, 516-522. [CrossRef] 
71. Mahalingam, D.; Goel, S.; Aparo, S.; Patel Arora, S.; Noronha, N.; Tran, H.; Chakrabarty, R.; Selvaggi, G.; Gutierrez, A.; Coffey, M.; et al. A Phase II Study of Pelareorep (REOLYSIN ${ }^{\circledR}$ ) in Combination with Gemcitabine for Patients with Advanced Pancreatic Adenocarcinoma. Cancers 2018, 10, 160. [CrossRef] [PubMed]

72. Hallin, J.; Engstrom, L.D.; Hargis, L.; Calinisan, A.; Aranda, R.; Briere, D.M.; Sudhakar, N.; Bowcut, V.; Baer, B.R.; Ballard, J.A.; et al. The KRAS(G12C) Inhibitor MRTX849 Provides Insight toward Therapeutic Susceptibility of KRAS-Mutant Cancers in Mouse Models and Patients. Cancer Discov. 2020, 10, 54-71. [CrossRef]

73. Kinsey, C.G.; Camolotto, S.A.; Boespflug, A.M.; Guillen, K.P.; Foth, M.; Truong, A.; Schuman, S.S.; Shea, J.E.; Seipp, M.T.; Yap, J.T.; et al. Protective autophagy elicited by $\mathrm{RAF} \rightarrow \mathrm{MEK} \rightarrow \mathrm{ERK}$ inhibition suggests a treatment strategy for RAS-driven cancers. Nat. Med. 2019, 25, 620-627. [CrossRef]

74. Weng, C.-C.; Ding, P.-Y.; Liu, Y.-H.; Hawse, J.R.; Subramaniam, M.; Wu, C.-C.; Lin, Y.-C.; Chen, C.-Y.; Hung, W.-C.; Cheng, K.-H. Mutant Kras-induced upregulation of CD24 enhances prostate cancer stemness and bone metastasis. Oncogene 2019, 38, 2005-2019. [CrossRef]

75. Yang, Q.; Lang, C.; Wu, Z.; Dai, Y.; He, S.; Guo, W.; Huang, S.; Du, H.; Ren, D.; Peng, X. MAZ promotes prostate cancer bone metastasis through transcriptionally activating the KRas-dependent RalGEFs pathway. J. Exp. Clin. Cancer Res. 2019, 38, 1-17. [CrossRef] [PubMed]

76. Merrick, B.A.; Phadke, D.P.; Bostrom, M.A.; Shah, R.R.; Wright, G.M.; Wang, X.; Gordon, O.; Pelch, K.E.; Auerbach, S.S.; Paules, R.S.; et al. Arsenite malignantly transforms human prostate epithelial cells in vitro by gene amplification of mutated KRAS. PLoS ONE 2019, 14, e0215504. [CrossRef] [PubMed]

77. Wang, X.-S.; Shankar, S.; Dhanasekaran, S.M.; Ateeq, B.; Sasaki, A.T.; Jing, X.; Robinson, D.; Cao, Q.; Prensner, J.R.; Yocum, A.K.; et al. Characterization of KRAS Rearrangements in Metastatic Prostate Cancer. Cancer Discov. 2011, 1, 35-43. [CrossRef]

78. Kharmate, G.; Hosseini-Beheshti, E.; Caradec, J.; Chin, M.Y.; Tomlinson Guns, E.S. Epidermal Growth Factor Receptor in Prostate Cancer Derived Exosomes. PLoS ONE 2016, 11, e0154967.

79. Kharmate, G.; Hosseini-Beheshti, E.; Caradec, J.; Chin, M.Y.; Tomlinson Guns, E.S. Correction: Epidermal Growth Factor Receptor in Prostate Cancer Derived Exosomes. PLoS ONE 2016, 11, e0157392. [CrossRef] [PubMed]

80. Nickols, N.G.; Nazarian, R.; Zhao, S.G.; Tan, V.; Uzunangelov, V.; Xia, Z.; Baertsch, R.; Neeman, E.; Gao, A.C.; Thomas, G.V.; et al. MEK-ERK signaling is a therapeutic target in metastatic castration resistant prostate cancer. Prostate Cancer Prostatic Dis. 2019, 22, 531-538. [CrossRef]

81. Vanni, I.; Tanda, E.T.; Dalmasso, B.; Pastorino, L.; Andreotti, V.; Bruno, W.; Boutros, A.; Spagnolo, F.; Ghiorzo, P. Non-BRAF Mutant Melanoma: Molecular Features and Therapeutical Implications. Front. Mol. Biosci. 2020, 7, 172. [CrossRef] [PubMed]

82. Dietrich, P.; Kuphal, S.; Spruss, T.; Hellerbrand, C.; Bosserhoff, A.K. Wild-type KRAS is a novel therapeutic target for melanoma contributing to primary and acquired resistance to BRAF inhibition. Oncogene 2017, 37, 897-911. [CrossRef] [PubMed]

83. Missero, C. The genetic evolution of skin squamous cell carcinoma: Tumor suppressor identity matters. Exp. Dermatol. 2016, 25, 863-864. [CrossRef] [PubMed] 